\title{
ENTRE FIOS E CORTES: A PESQUISA COMO PROCESSO VIVIDO EM ALINHAVADO TEÓRICO-METODOLÓGICO
}

\begin{abstract}
Juliana Maddalena Trifilio Dias ${ }^{1}$
Resumo: Quem está no universo da pesquisa provavelmente já se perguntou: vou defender minha dissertação, tese ou TCC com o projeto que ingressei? A resposta para esta pergunta pode revelar modos de fazer ciência e concepções sobre trajetórias de pesquisa. Há quem responda: sim, será o mesmo. Mas há quem não vá esboçar esta certeza. E foi nesta possibilidade da dúvida que construí a pesquisa. Então, já anuncio que pratico um fazer da pesquisa que é construído no próprio percurso e não a priori. Com este modo, o caminho não é linear, ainda que o fio possa ser o mesmo. $\mathrm{O}$ artigo apresenta uma trajetória de pesquisa de doutoramento construída e vivida no encontro de fios teóricos, no tecer metodológico e em muitos cortes e alinhavados. A luz do artigo está sob a trajetória em sua potência reveladora de movimentos de uma pesquisadora em direção ao lugar geopsíquico.
\end{abstract}

Palavras-chave: Lugar geopsíquico; Inconsciente; Pesquisa; Psicanálise; Geografia Humanista.

\section{Apresentando os fios}

Costurar, tecer ou fiar? Difícil escolher um verbo que se aproxime da imagem que tento apresentar com o título deste artigo ${ }^{2}$. Aliás, já tenho na construção dessa frase algo sobre nosso funcionamento: o pensar, o ato de criar imagens e a constante tentativa de expressar em palavras aquilo que estamos construindo. Neste caso, a escolha por palavras que remetem a uma imagem do costurar, do tecer e do fiar não foi aleatória. Com elas quero expressar, através de palavras, aquilo que se constituiu como um processo de pesquisa construído ao longo do próprio caminhar. Por isso, recorrerei a este recurso de linguagem para apresentar ao leitor um artigo como memorial de pesquisa. Uma opção frente às imagens do pensar que intento apresentar sobre o modo como a pesquisa, entendida como processo, foi sendo construída e vivida.

Quem está no universo da pesquisa provavelmente já se perguntou: vou defender minha dissertação/tese com o projeto que ingressei? A resposta para esta pergunta pode revelar modos de fazer ciência e concepções sobre trajetórias de pesquisa. Há quem responda: sim, será o mesmo. Mas há quem não vá esboçar esta certeza. E foi nesta possibilidade da dúvida que construí a pesquisa. Então, já anuncio que pratico um fazer da pesquisa que é construído no próprio percurso e não a priori.

\footnotetext{
${ }^{1}$ Professora da Faculdade de Educação da Universidade Federal de Juiz de Fora, na área de Ensino de Geografia. juliana.maddalena@ufjf.edu.br

2 Artigo inspirado no texto de Qualificação de doutorado (2017) da pesquisa "A palavra como mapa nas geografias mentais dos lugares", vinculada ao Programa de Pós-Graduação em Geografia pela Universidade Estadual de Campinas (Unicamp) sob orientação do prof. Dr. Eduardo Marandola Júnior.
} 
Com este modo, o caminho não é linear, ainda que o fio possa ser o mesmo. Seguiremos com o fio de construção da pesquisa no caminhar.

\section{Fios e caminhos}

Ingressei no doutoramento no Programa de Pós-graduação em Geografia da Unicamp com o projeto "Experiências urbanas e constituição do sujeito: diálogos entre Memória e epistemologia da Geografia" e durante o percurso acreditei que havia mudado de projeto, mas ao refletir e escrever o texto de Qualificação, optei por retomá-lo como parte fundamental para um caminho que se deu em forma espiralada. Foi um projeto que paradoxalmente era o mesmo, mas, também, não foi mais o mesmo. A imagem do espiral traz um fio que é o mesmo, que se afasta do ponto inicial e que se aprofunda em sua terceira dimensão. No ponto inicial daquele caminho apresentei o seguinte resumo:

Este projeto de pesquisa busca compreender em que medida a epistemologia da Geografia tem servido como ancoragem teórica e reflexiva em uma de suas principais categorias de análise do espaço geográfico - o lugar, a partir da discussão entre experiência urbana, Memória e Fenomenologia. Sua proposta teórica e metodológica encontra-se no esteio da Fenomenologia e da Geografia Humanista Cultural através da narrativa de sujeitos sobre suas experiências urbanas contemporâneas no lugar. Trate-se de um projeto repleto de perguntas que revelam um desejo de estudo e movimento investigativo pautado num referencial em sua potencialidade de apropriação. Com este desejo, o intuito é percorrer o campo do saber geográfico a fim de compreender essa relação intrínseca entre experiência e atitude reveladas entre memórias e visão de mundo e, com isso, permitir a aproximação da essência da memória do sujeito em suas relações no lugar (DIAS, 2014, p. 2).

Desalinhando tal resumo é possível encontramos os traços fortes que continuaram a integrar o fio de construção da pesquisa: o mergulho na epistemologia da Geografia; a reflexão sobre o lugar a partir da experiência, o investimento teórico nos campos da Memória e da Fenomenologia, a permanência no esteio da Geografia Humanista e a narrativa de sujeitos sobre suas experiências com o lugar. No entanto, ao caminhar, este fio também foi entrecortado.

Lendo e relendo a combinação do resumo inicial com estas expressões destacadas, vejo que a ideia de pensar este processo como um fio paradoxal, entre ser e não ser o mesmo, é algo que se apresenta expresso na repetição das palavras e expressões. Não a repetição como limitação de vocabulário, mas como permanência e aprofundamento nelas mesmas. Então, apesar de estarem igualmente grafadas, já produziram diferentes sentidos no decorrer do doutoramento. A geografia, o lugar, a memória, a fenomenologia, a experiência, a narrativa e os sujeitos não eram mais os mesmos, vamos segui-los no fio espiral. Mas vamos nos voltar aos deslocamentos e produção de sentidos que foram construídos e alinhavados naquela pesquisa.

No início do curso estava focada em investigar questões referentes ao lugar, à constituição do sujeito e à relação entre a memória e experiência urbana. Enxergava uma ligação íntima entre lugar 
e memória na constituição do sujeito a partir de suas experiências vividas na cidade. Queria conhecer estas experiências, compreender suas marcas na pessoa a partir de seus afetos pelos lugares. Mas muitos fios estão soltos neste parágrafo. Vamos desalinhá-lo.

Quando as pessoas me interrogavam sobre o que pesquisava, duas palavras, repetidamente, respondia: lugar e memória. A memória era algo que intuía como horizonte de estudos como campo que me permitiria uma possível aproximação com a Geografia Humanista e algo que sinalizava um desejo de investigar o que se passa no interior de cada um de nós.

Aquela temática era algo que me encantava desde quando, muitos anos antes, havia me inserido como membro do grupo CRONOS - História ensinada, memória e saberes escolares ${ }^{3}$. Mas estar num grupo predominantemente de historiadores fez com que uma necessidade se instalasse: a constante pergunta pela geografia. Geografia e memória se aproximam? Como? Fui, aos poucos, amadurecendo esta relação e sempre o lugar se despontava como a noção que me permitiria refletir sobre a memória no interior da Geografia.

Naquele momento as reflexões circulavam em torno de uma possível aproximação entre lugar e memória. Então, com o referencial de Maurice Halbwachs (2006), Andreas Huyssen (2000), David Lowenthal (2015), Sonia Miranda e Lana Siman (2013), Pierre Nora (1993), Michael Pollak (1989), Simon Schama (1996) e Paul Ricoeur (2007), apresentei a ideia de que o campo da memória a considera como prática individual, social e coletiva, que ela se apoia em situações que vivemos, experiências que acumulamos e em objetos que despertam nossas relações estabelecidas em algum momento e lugar. Essa perspectiva trabalha com a memória a partir de narrativas, entre o lembrar e o esquecer como operação que desenvolvemos para selecionarmos coisas do passado. A preocupação não estava só no ato de lembrar, mas também que nos lembramos daquilo que é importante em nossas vidas. Mas o modo como apresentei tal reflexão naquele projeto não me permitiu ir além de apenas estabelecer cruzamentos ou interseções com a Geografia.

Outro fio fundamental na elaboração do projeto foi a perspectiva de lugar que vigorava em minhas reflexões. A noção de lugar que me levou ao doutoramento foi a de Yi-Fu Tuan (2013) e era centralizada na expressão "o espaço se torna lugar" e na relação entre experiência, visão e atitude no mundo. Algo que já sinalizava o interesse em considerar como indissociável o mundo exterior e nosso interior, como em Yi Fu Tuan (2012), na obra organizada por Antônio Christofoletti (1982), em Werther Holzer (2010, 2016), e em Edward Relph (2012).

Com essa visão sobre lugar, passei a considerar, naquele momento, a imagem de algo que reúne, aglutina, converge e recolhe para si experiências e significados (RELPH, 2012; SARAMAGO,

\footnotetext{
${ }^{3}$ Grupo coordenado pela profa Dra Sonia Regina Miranda na Faculdade de Educação da Universidade Federal de Juiz de Fora.
} 
2012). Nesta perspectiva, o lugar não é toda e qualquer localidade, mas aquela que tem significância afetiva para uma pessoa ou grupo de pessoas e o estudo do lugar deve procurar analisar seus sentimentos e ideias. Para Tuan (2013), o espaço familiar torna-se lugar, os acontecimentos podem gerar um sentimento profundo pelo lugar e é "pausa no fluxo do tempo", era neste sentido que a investigação da pesquisa se orientava. Todavia, não havia me questionado: o que converge? Como? Por quê?

Era notório que estava ancorada teórico e metodologicamente na Geografia Humanista, que buscava compreender o sujeito em sua constituição a partir da relação indissociável com o lugar, mas tudo estava apenas no plano do desejo e sem a clareza que só veio a posteriori. E o fiar continuava.

Ao ingressar no doutorado, também me tornei membro do NOMEAR - Grupo de Pesquisa Fenomenologia e Geografia ${ }^{4}$ e passei a ter contato com o universo da Fenomenologia. O que era desconhecido se tornou um desafio para que conseguisse me aproximar de um novo referencial. Então, ao mesmo tempo em que as leituras do grupo eram feitas, Eduardo Marandola Jr., como orientador da tese, me indicou que iniciasse as leituras dos filósofos para o doutorado. A partir da temática que apresentava e com a necessidade de estudar a Fenomenologia, as leituras começaram pelo filósofo Gaston Bachelard (1993, 2009, 2010) e por Paul Ricoeur (2007).

Concomitantemente a este processo, desenvolvia uma pesquisa sobre "o que dizem os filósofos e geógrafos humanistas, lidos pelo GHUM, sobre crianças e infância?". Como integrante do Grupo de pesquisas Geografia Humanista Cultural - GHUM', apresentei a referida pesquisa em 2015 sob o título: "Gaston Bachelard e infância: primeiras aproximações." Foi quando um novo fio entrelaçou o tecer dessa pesquisa.

Para Dias (2016), a partir das expressões do próprio filósofo, a criança como filha do cosmos torna-se dona de seus devaneios e conhece a ventura de sonhar. É uma concepção de infância que não tem fim em uma ou noutra idade, e sim, naquela em ainda dura em cada um de nós. É abertura à vida e a noção de continuidade também permitem que a infância possa ser reimaginada. O livro "A poética do devaneio" possui um capítulo dedicado à infância: "Os devaneios voltados para a infância", nele sua tese central é

reconhecer a permanência, na alma humana, de um núcleo da infância, uma infância imóvel mas sempre viva, fora da história, oculta para os outros, disfarçada em história quando a contamos, mas que só tem um ser real nos seus instantes de iluminação - ou seja, nos instantes de sua existência poética (BACHELARD, 2009, p. 94).

\footnotetext{
${ }^{4}$ Grupo coordenado pelo profo Dro Eduardo Marandola Jr. na Faculdade de Ciências Aplicadas da Unicamp.

${ }^{5} \mathrm{Na}$ ocasião o grupo era coordenado pelos professores Dro Werther Holzer (UFF) e Lívia de Oliveira (Unesp hoje in memoriam) e sediado na Escola de Arquitetura e Urbanismo na Universidade Federal Fluminense.
} 
O autor destaca a infância em sua permanência, com outra relação temporal, íntima e com forte relação com a existência poética. Um tempo nascido como eixo investigativo a partir da noção de memória. Estava diante de uma concepção de infância cuja ideia de continuidade me permitia refletir sobre o tempo em nossa constituição. Continuei envolvida com as leituras de Bachelard enquanto tentava cruzar os fios entre aquilo que se apresentava e aquilo que era a ideia inicial da pesquisa.

Com a obra "A poética do espaço", Bachelard (1993) questiona se o que foi terá sido mesmo. Ao estar diante de trechos que misturam e relacionam recordação e imaginação à memória, fiquei a me interrogar se nossas memórias eram compostas por experiências vividas ou se poderia pensá-las, também, como no ato de imaginar as experiências passadas vividas. Então, quando acreditara fechar a temática investigativa em imaginação e memória nas duas obras citadas de Bachelard, os questionamentos se intensificaram ao pensar sobre essa relação na infância como continuidade. Quando o autor discorre sobre "os devaneios voltados para a infância" nossa unidade pode ser compreendida também pelas narrativas de outras pessoas, o que nos permite imaginar e criar imagens e lembranças dos tempos de nossa primeira vida e sugere que nossa infância pode ser reimaginada (DIAS, 2016). Se para o filósofo a imaginação lê os microfilmes da memória, o que registramos nesses filmes? Ora, se as experiências podem construir memórias, o que dizer sobre aquelas criadas a partir da imaginação anteriores à experiência? Eis o ponto em que me encontrava diante da intenção em refletir sobre imaginação e memória, com ancoragem em Bachelard e ênfase na infância, mas sem conseguir responder sobre esta ideia de anterioridade da experiência.

Para o autor, nesta união entre imaginação e memória podemos imaginar reviver o passado. "Eu retinha com uma memória imaginária toda infância que ainda não conhecia e que no entanto, reconhecia" (BACHELARD, 2009, p. 117). A fluidez entre a infância e a velhice através da memória ocorre porque para o autor, existe uma permanência na alma humana por meio de um núcleo que une imaginação e memória, um núcleo móvel da infância que está "sempre viva, fora da história, oculta para os outros, disfarçada em história quando a contamos, mas que só tem um ser real nos instantes de iluminação, ou seja, nos instantes de sua existência poética” (BACHELARD, 2009, p. 94). Esta infância em sua permanência e núcleo habita em nós, ela é continuidade, como também é descontinuidade, inclusive no narrar ao outro. Ela não é uma infância restrita como fase da vida e ao falarmos sobre ela nossas continuidades e descontinuidades vão surgindo em cada relato de experiência vivida (DIAS, 2016).

Esta concepção de infância foi, naquele início do doutoramento, um dos fios reflexivos mais fortes que encontrei e que passei a tensionar. O que era uma discussão apenas sobre a memória passou a englobar a imaginação, o que não possuía recorte na fase da vida passou a destacar a infância 
e o que não possuía lugares definidos passou a observar onde encontrar crianças. Era um universo investigativo que ia se desenhando e repleto de inquietações e incertezas.

A obra "A Poética do espaço" de Bachelard (1993) apresenta a "casa como nosso canto do mundo" (BACHELARD, 1993, p. 22) e afirma que "as lembranças do mundo exterior nunca terão a mesma tonalidade das lembranças da casa" (BACHELARD, 1993, p. 23). Seguindo este raciocínio, o filósofo aponta que "o espaço chama a ação, e antes da ação a imaginação trabalha" (BACHELARD, 1993, p. 27), logo, me perguntei, como refletir sobre as relações topofílicas e a experiência geográfica para além da dimensão física do espaço? (DIAS, 2019). Se na infância a experiência é posterior às imagens e a imaginação pode anteceder a ação nos lugares, como são os lugares imaginados na infância? Assim, a infância estaria na origem das maiores ou mais significativas paisagens. Na infância construímos paisagens imaginárias. Ora em lugares nunca antes visitados, ora presentes naqueles que outrora já vistamos, o que conseguimos é transver a paisagem.

Não podemos perder de vista que desde o início estava voltada para questões subjetivas. Nomeava cada uma delas de forma diferente, como a memória, por exemplo. Mas este fio sempre teci e meu teceu. O ponto é como este fio foi se alinhando, se cortando e não sendo mais o mesmo, ainda que sendo.

Então, uma segunda versão do projeto já em curso no doutorado procurava enfrentar a essência geográfica - lugar - na constituição do sujeito pelo atravessamento de questões como: em que momento de sua vida suas lembranças, expectativas e vínculos com o lugar são convidados a constituírem o ser na infância em continuidade? De que se lembram? De quais lugares? Como se lembram?

Entretanto, certo ocorrido em uma determinada disciplina alterou bruscamente o curso daquela pesquisa. Na disciplina "Seminários", cursada na Unicamp, cada aluno enviou seu projeto de ingresso para que pudesse ser lido por um professor externo e debatido por toda turma. Apresentei, naquele terceiro semestre, meu projeto já com algumas atualizações, como a inserção da noção de infância de Gaston Bachelard que passou a orientar meu referencial. Naquele momento, a ideia de pesquisar infância havia tomado centralidade e se somava ao lugar, memória e experiência. Minha dúvida passou a ser se trabalharia com crianças na infância ou se abordaria a infância sem delimitar a pesquisa com crianças. Então, levei questões para serem debatidas naquela disciplina, como por exemplo: "O sujeito se lembra de quê? E faz o que com o que lembra? Como as experiências dos sujeitos apresentadas por suas memórias podem permitir conhecer seus lugares? Ou ainda, quando aqueles espaços da infância se tornam lugares?". Ao final pedi à turma e aos professores que me ajudassem no que chamei de ponto crucial para a pesquisa: "Crianças ou adultos? Crianças na infância 
ou adultos sobre a infância? Como a criança constitui seus lugares? Como o adulto constitui seus lugares a partir da infância? De quais lugares os adultos se lembram de suas infâncias?". ${ }^{6}$

Todavia, enquanto aguardava o desfecho da discussão sobre o ponto crucial, um colega da classe levantou a mão, pediu a palavra e disse: "Não sei porque vou te falar isso, nem se devo falar, mas me lembrei do meu avô. Já velhinho dei pra ele um caderno de presente e ele começou a escrever sobre sua vida, sobre seu passado. Ele me deu o caderno de sua vida de presente e quero te mostrar. $E$ aproveito para perguntar, você fala em criança e fala em adultos, mas por que não pesquisar os velhos?".

Algo muito forte havia me interpelado e não poderia apressadamente responder ao que havia se apresentado. Fiz um longo silêncio e guardei aquela sensação que estava sentido. Aquele momento ecoou muito tempo antes de decidir o que fazer na sequência da pesquisa. Não havia como ignorar e seguir com um plano prévio. Se a pesquisa é feita no próprio caminhar, as pausas fazem parte do caminho. Naquela pausa, a dúvida se desdobrou em considerar possibilidades de pesquisa com crianças, adultos, velhice e infância na relação com a memória e lugar.

Para tentar clarear aquela dúvida e os caminhos que surgiram, passei a fazer o campo da pesquisa com crianças e idosos e a fazer os registros de cada uma delas. Trabalhei com duas conversas biográficas (DIAS, 2019) com os idosos e ouvir histórias de vida e lugares foi algo que me encantou demasiadamente. Durante o doutoramento (DIAS, 2019), me aventurei a olhar geograficamente nosso mundo interior, para aquilo que está para além da materialidade e dos vestígios encontrados no lugar. Então, ampliando com os verbos destacados, me perguntei (DIAS, 2019): é possível conhecer as diferentes temporalidades e geograficidades da experiência humana, mas como nos orientar nestes outros tempos e lugares? Como localizar? Como nos orientar? Como é possível se deslocar? Como são feitos e lidos os registros dessas experiências? Como decodificá-los? Como compreender a experiência humana em seus diferentes tempos e lugares?

Iniciei o campo da pesquisa sem uma hipótese que me engessasse e que me fizesse procurar resultados comprobatórios. Não havia, naquele momento, o que comprovar ou refutar, o que existia era uma abertura para que o fenômeno se revelasse no caminhar (DIAS, 2019). E isto aconteceu, revelando continuidades e descontinuidades

O próprio trabalho de campo torna-se, portanto, uma experiência da cidade, durante a qual o pesquisador procura envolver-se, de forma intencional e desenraigada, com a própria cidade. Mas, para perscrutar os sentidos originais da relação das pessoas com o espaço, é fundamental deixar que a cidade se revele. Colocar entre parênteses (suspendendo os conhecimentos prévios) é importante, para que o objeto revele-se ao pesquisador, partindo daí a interação tão desejada que gera o conhecimento. [...]

\footnotetext{
6 Episódio narrado na tese "Lugar geopsíquico: contribuições da Psicanálise para uma epistemologia da Geografia”, em 2019, no Programa de Pós-graduação em Geografia, na Unicamp.
} 
Antes, o campo tem o objetivo do descobrimento, esperando-se que dele venham à tona hipóteses. Por isso, o campo, em primeiro lugar, serve à descrição; só mais tarde ele poderá ser utilizado para a reflexão sobre hipóteses ali surgidas e nas análises do pesquisador (MARANDOLA JR; PAULA; PIRES, 2006, p. 463).

Entre fios, pausas e caminhos estive às voltas com manifestações da experiência subjetiva de cada participante e isto significou estar atenta, em estado de vigília, ao que pudesse emergir na vida cotidiana. Através de conversas biográficas (MARANDOLA JR, 2014; DIAS, 2019) pude ouvir as narrativas das pessoas em uma reciprocidade que uma conversa supõe, de modo que aquilo que era exposto sobre suas vidas fosse respeitado e acolhido nesta pesquisa.

Cada uma das conversas biográficas me permitiu estar em contato com as pessoas, seus mundos e suas narrativas que me apresentavam mundos íntimos em sua profundidade e naquilo que era possível de ser dito a uma pesquisadora. Procurei estar atenta às palavras, aos sorrisos, silêncios, constrangimentos, preocupações, olhares, receptividade, recusa, gestos que compunham o universo do narrar. Pude me aproximar daquilo que havia sido vivido e lembrado por cada pessoa, num exercício que me exigia escuta e imaginação.

Concomitante às conversas biográficas e às questões que surgiam, continuava as leituras de Paul Ricoeur sobre tempo e narrativa e novos elementos foram emergindo. E continuava a questionar: "como o tempo é visto e discutido na Geografia?" (DIAS, 2018). Construir uma discussão apenas teórica sobre tempo não foi algo que me capturou e continuava a refletir sobre as questões que emergiam da empiria do campo de pesquisa. Todavia, o tempo parecia unir infância e velhice entre si e com o lugar e a memória. Que tempo era aquele? Estava começando a pensar em um tempo para além do cronológico e me aproximava da ideia do tempo que se torna humano. Estava diante do grande fio condutor dessa pesquisa. O que havia de tão forte entre o lembrar, o narrar, a infância e as experiências com os lugares?

Um dos eixos que assinalo no pensamento de Paul Ricoeur é o que Santo Agostinho discorre e confronta sobre a alma humana a partir da reflexão sobre a intentio e a distentio animi e a noção de triplo presente. A partir das marcas na alma é possível nos lembrarmos daquilo que sentimos e vivemos em determinada circunstância, mesmo que no momento da recordação não tenhamos o mesmo sentimento. Os afetos marcam a alma e geram outros sentidos no ato de lembrar (DIAS, 2018).

Para Agostinho (1999), a noção de triplo presente coloca passado e futuro no presente por meio da memória e da expectativa sob um longo futuro e um longo passado. No presente do presente, no presente do passado e no presente do futuro. Em uma relação distendida entre expectativa (presente do futuro), memória (presente do passado) e atenção (presente do presente). Passado e futuro coexistindo no presente através da memória e expectativa das coisas vividas ou de antemão 
anunciadas e na composição de um presente indivisível. Dessa forma, nossas experiências vividas nos lugares são gravadas na alma e se apresentam como vestígios no presente.

Esta foi uma reflexão que não esteve presente na versão final da tese, mas que, como percurso, foi fundamental para a relação entre tempo, inconsciente e lugar. Este destaque é importante para não perdermos de vista que nada é perdido em uma pesquisa, desde que seja concebida como caminho e caminhar.

Naquele contexto, a presença do passado no presente foi um fio que passou a ter visibilidade na pesquisa e convergência nas reflexões. E uma frase que ouvi no campo de pesquisa me permitiu o cruzamento de tantos fios: "olha, ali era meu quarto".

Há mais de um ano estive na casa de D. Celma ${ }^{7}$ e entre cafés, broas e risadas, ela me contou sobre sua vida. Até que num determinado momento ela apontou para fora da janela e disse: "olha, ali era meu quarto". Eu olhei e vi uma casa recém construída. Ela continuou a me mostrar onde brincava, onde se escondia e onde eram os outros quartos da casa. Aquilo mexeu muito comigo. A casa dela não estava mais lá e, ainda assim, falava como se estivesse enxergando seu quarto de décadas atrás. Naquele instante da narrativa, me deparei com algo que geograficamente não conseguia responder. Foi algo tão forte que passei a ficar com os efeitos daquela conversa por muito tempo. Ao lembrar daquela inquietação posso assumir a referida conversa como uma marca para pesquisa, enfatizá-la como um fio fundamental e como um corte que definiu a continuidade do processo de doutoramento.

Durante este processo que tenho narrado, duas coisas aconteciam: continuava minhas leituras e relutava, de alguma forma e comigo mesma, em escrever o texto de Qualificação. Algo parecia não fechar, algum fio faltava no tecer, no processo. Naquele momento, havia começado o texto numa longa discussão sobre tempo, memória e lugar a partir de suas interseções. Já desejava trabalhar com cruzamentos, mas definitivamente, algo não me permitia realizá-los. Algo me faltava para prosseguir com as reflexões e escrita, mas não sabia o que poderia ser. Na insistência, saía da frente do computador e voltada a me debruçar sob a leitura da obra de Paul Ricoeur (2007) "A memória, a história e o esquecimento". Este livro marcou meu ingresso no doutorado, mas curiosamente, não havia concluído sua leitura.

Certo $\mathrm{dia}^{8}$ em que fazia a leitura me deparei com uma determinada citação que muito chamou minha atenção. A menos de cinquenta páginas para o término do livro (num total de 535 páginas) vi que Paul Ricoeur citou Sigmund Freud e fui ao final das referências para ver de qual texto se tratava. Para minha feliz surpresa identifiquei que Ricoeur havia utilizado e, portanto, lido treze

\footnotetext{
${ }^{7}$ Nota de campo presente na tese "Lugar geopsíquico: contribuições da Psicanálise para uma epistemologia da Geografia", em 2019, no Programa de Pós-graduação em Geografia, na Unicamp.

${ }^{8}$ Nota de campo presente na tese "Lugar geopsíquico: contribuições da Psicanálise para uma epistemologia da Geografia", em 2019, no Programa de Pós-graduação em Geografia, na Unicamp.
} 
textos/livros de Sigmund Freud. Pensando no universo acadêmico, este número de obras, em sua diversidade e quantidade, indica um movimento de leitura em direção ao autor e sua temática. Havia uma aproximação teórica e conceitual que até aquele momento não enxergava.

Aquela surpresa me fez retornar a cada citação de Freud ao longo do livro. Curiosamente, me reencontrei com páginas que, de algum modo, havia deixado sem grifos ou anotações. Reli cada uma daquelas páginas e fui me encantando por cada trecho que, dessa vez, grifava e anotava. Não havia me dado conta que Ricoeur foi um leitor de Freud e quando percebi, comecei novas buscas que intersecionavam os dois pensadores.

As surpresas continuavam, ao menos para mim. Ao buscar por Ricoeur e Freud comecei a encontrar artigos, teses e livros. E este foi o caminho que encontrei entre o que estava construindo e aquilo que estava por vir. A cada leitura fui realizando dois movimentos: me afastava da obra de Paul Ricoeur e me aproximava da obra de Sigmund Freud. O fiar estava com outro fio.

Na sequência daquilo que tenho chamado como desvelar na pesquisa, passei a integrar um grupo de estudos em psicanálise sobre Freud. Um novo universo reflexivo se abriu e com ele dois sentimentos paradoxais: o entusiasmo com a vontade de estudar o autor e a preocupação com a continuação da pesquisa a partir da interseção que desejava realizar. Afinal, estava na segunda metade do doutoramento.

\section{Tecer e co-fiar com a psicanálise}

A vontade de estudar Freud foi acompanhada pelo volume e intensidade de leituras que passei a realizar. Algo que precisaria ser assumido e delimitado para elaboração da tese. Para uma geógrafa, o encontro com a psicanálise freudiana e lacaniana trouxe muitas questões. Tratava-se de, no mínimo, refletir sobre a base teórica construída a partir da ideia de inconsciente. Neste caso, minha aproximação com o pensamento freudiano e lacaniano se deu em uma geógrafa identificada com a Geografia Humanista. Este foi o fio teórico e metodológico da tese, mas não perca de vista que como do início até o momento em que isto se desvelou e foi para versão final do trabalho.

Foram muitos fios e possibilidades de tecer que surgiam e me encantavam, mas precisava me rever como geógrafa entre meus pares. Foi quando comecei a pesquisar qual era a incidência dessa temática em buscadores nacionais e internacionais, bem como as associações de geógrafos internacionais. Então, de modo surpreendente a mim, encontrei os livros "Psychoanaliytic Geographies", organizada por Paul Kingsbury e Steve Pile (2014) e "Real Cities: Modernity, Space and the Phantasmagorias of City Life" de Steve Pile (2005).

A partir dos livros tive acesso às pesquisas, às publicações e aos pesquisadores norteamericanos, espanhóis, franceses, argentinos e britânicos. A partir dessa produção pude visualizar em qual contexto esta pesquisa se inseria, qual a possibilidade de contribuição à geografia brasileira e 
quais recortes poderia realizar a partir dos fios que tenho alinhado nesse processo. Este encontro foi importante nele mesmo e por promover reencontros com geógrafos que não havia lido para tese. Voltei aos textos de John Wright (Terrae incognitae: the place of the imagination in Geography, 1947), David Lowenthal (Geography, Experience, and Imagination: Towards a Geographical Epistemology, 1961), Eric Dardel (O homem e a terra: natureza da realidade geográfica, 2011) e à potente produção na geografia brasileira contemporâneos Eduardo Marandola Jr., Lívia de Oliveira e Werther Holzer.

Com as leituras psicanalíticas sobre o inconsciente e o aparelho psíquico, uma frase que ouvi no campo da pesquisa voltou com força em meu horizonte reflexivo: "olha, ali era meu quarto". Comecei a me questionar como geograficamente poderia pensar em conceitos da Psicanálise para compreender geograficamente aquela frase que ouvi de D. Celma. A partir daquele momento passei a considerar o lugar a partir da realidade psíquica.

A geografia como experiência profunda do humano nos convoca para que possamos nos lançar ao desconhecido, nos aventurar por entre montanhas, florestas, céus e mares (DIAS, 2019). Muitas vezes sentimos atração ou repulsão por coisas, pessoas e lugares sem que tenhamos alguma explicação consciente para isso. Já observou que em determinados lugares você se sente confortável, atraído, em paz, relaxado, seguro, alegre, acolhido ou com vontade de permanecer (DIAS, 2019)? Em contrapartida, em outros lugares já se sentiu cansado, desconfortável, angustiado, com medo, inseguro ou com vontade de ir embora?

São muitas possibilidades de respostas que se singularizam na relação que cada um de nós estabelece com a Terra. Compreender a realidade psíquica no pensamento geográfico nos faz, efetivamente, considerar a pluralidade que pauta nossa geograficidade (DIAS, 2019).

Nesta imersão teórico e metodológica, com os $\operatorname{conceitos}^{9}$ psicanalíticos de realidade psíquica - Chemama (1995); Laplanche e Pontalis (1997); Freud [2019 (1900)], topologia - Lacan (2003 [19611962]), transferência - Freud [2010 (1912b)]; Freud [2010 (1915b)]; LACAN (2010 [1960-1961]), linguagem e inconsciente - Freud [2010 (1915a)]; Freud [2010 (1912a)]; Freud [2010 (1920)]; Freud [2011 (1923)]; LACAN (1999 [1957-1958]), um novo conceito foi apresentado à comunidade geográfica: lugar geopsíquico (DIAS, 2019). A tese inaugurou um encontro entre Geografia e Psicanálise e apresentou uma nova perspectiva para o conceito de lugar.

Esta construção ocorreu em adensamento ao pensamento do geógrafo Yi-Fu Tuan e no movimento produzido por perguntas que me fazia. Sempre li e ouvi que o lugar é um espaço de afeto. Mas por quê? O que afeta? Como afeta? Como algo transforma ou significa um lugar? O que acontece ali? O que o sujeito narra sobre si a partir do lugar? O que seria um lugar como centro de significância?

\footnotetext{
${ }^{9}$ Neste artigo, enfatizei o processo de pesquisa, dessa forma, optei por não adentrar nos conceitos que estão presentes na tese.
} 
Estas perguntas foram fundamentais na busca pelo entendimento do lugar geopsíquico a partir dos vínculos que criamos com lugares e pessoas.

As experiências são vividas com intensidades diferentes, seja pela duração, pela energia despendida entre a experiência vivida e o registro de uma impressão, pela qualidade ou modo como a experiência foi vivida (DIAS, 2018). Elas estão diretamente ligadas ao lugar geopsíquico.

Experiência que marca. Mas a marca não é presença consciente o tempo todo, então ela se transforma em esquecimento. Um esquecimento que não é sepultado, mas que pode ser manifestado, pode ser relembrado e pode ser comunicado a outra pessoa. Nos lembramos que esquecemos de algo. Então também existe lembrança que não é a experiência em si, mas o que ficou dela, seja em imagens ou efeito. Trata-se da lembrança em linguagem.

Se o lugar pode ser disparador, o que a pessoa que ali viveu uma experiência vê e que a pessoa ao seu lado não enxerga? A marca está impressa em uma pessoa que narra a outra a partir do que ela vê. Mas por que enxergam coisas diferentes estando no mesmo lugar? Como se dá este processo varia entre os sujeitos?

Nesta perspectiva, o lugar geopsíquico é constituído e vivido na dobra topológica entre o mundo interno e o mundo externo, com as dinâmicas terrestres e as dinâmicas psíquicas (DIAS, 2019). Ele é vivido junto, nesse externo que nos invade e nesse interno que transborda. Quais lugares seriam geopsíquicos para você? O que tem de você neste lugar? O que tem desse lugar em você?

\section{0 fiar continuará}

Com este grande fiar que foi tecido neste artigo, foi possível apresentar como se deu o processo de construção e delimitação da pesquisa. Uma pesquisa que foi sendo vivida em seu caminhar. Algo que foi possível e transformado em palavras no texto. Escolhi este modo de escrita e apresentação para me fidelizar ao que vou vivido. Sair de um ponto fixo abre a possibilidade de viver as distâncias, a partir dos desejos, da busca, do encontro, dos medos e do reconhecimento do ser no mundo. Numa perspectiva onde o lugar desenvolve nossa existência através experiência primitiva de enraizamento na Terra, de ser-no-mundo, (DIAS, 2016). Este lugar também é e está na escrita, na pesquisa e no dizer.

Neste processo do fiar, me rendi à força do encontro com a psicanálise. Uma força movente que me trouxe muitas incertezas, angústia, mas um desejo claro de estudar e pesquisar a partir, com e na Psicanálise. Então, me entreguei a isto. Considerar o lugar geopsíquico a partir das marcas que carregamos e olhá-lo a partir da realidade psíquica foi central na pesquisa. Assim como compreender a existência e os efeitos do Inconsciente em nosso modo de ser e estar na Terra.

A Tese (DIAS, 2019) se insere neste contexto e procurou refletir sobre as relações entre os mundos internos e mundos externos com ênfase no que ocorre nos mundos internos. Uma opção por 
olhar para a relação entre os dois mundos. Na Geografia, historicamente produzimos conhecimento sobre o mundo externo, então, para compreendermos as relações entre interno e externo precisamos nos aproximar e nos aprofundar em reflexões sobre nosso mundo interno (DIAS, 2019). Este mundo interno se torna plural em cada um de nós, envolve nosso psiquismo, nossos afetos, nossas memórias, nossos sonhos, nossos sentimentos, nossa imaginação, nossos sentidos e nossos pensamentos (DIAS, 2019).

O convite é para vivermos a pesquisa como caminho. Um caminho que poderá fazer sentido somente posteriormente, mas que poderá revelar a força de cada passo e alinhavado. Somos fios, nos constituímos entre fios, entrelinhas, no tecer, no fiar e no cortar. E você, pesquisador e pesquisadora, quais são seus fios?

Referências

AGOSTINHO, Santo. Confissões. São Paulo: Nova Cultural, 1999.

BACHELARD, Gaston. A intuição do instante. Campinas: Verus, 2010.

BACHELARD, Gaston. A poética do devaneio. São Paulo: WMF Martins Fontes, 2009.

BACHELARD, Gaston. A poética do espaço. São Paulo: Martins Fontes, 1993.

CHEMAMA, Roland. Dicionário de Psicanálise. Porto Alegre: Artes Médicas Sul Ltda, 1995.

CHRISTOFOLETTI, Antonio. Perspectivas da Geografia. São Paulo: Difel, 1982.

DARDEL, Eric. O Homem e a Terra: natureza da realidade geográfica. Trad. Werther Holzer. São Paulo: Perspectiva, 2011.

DIAS, Juliana Maddalena Trifilio. Lugar geopsíquico: contribuições da Psicanálise para uma epistemologia da Geografia. 2019. Tese (Doutorado em Geografia). Programa de Pós-Graduação em Geografia, Universidade Estadual de Campinas, 2019. $172 \mathrm{f}$.

DIAS, Juliana Maddalena Trifilio. Memória e lugar: entre a noção de indissociabilidade espaço-tempo e a reflexão sobre a experiência geográfica. Geograficidade, v. 8, n. 2, Inverno de 2018. p. 161-173, 2018.

DIAS, Juliana Maddalena Trifilio. Infância em Gaston Bachelard: reflexões sobre o ensino de geografia. Rev. abordagem gestalt., Goiânia, v. 22, n. 2, p. 162-170, dez. 2016.

FREUD, Sigmund. A interpretação dos sonhos. [1900] (Edição Cia das Letras das Obras Psicológicas Completas de Sigmund Freud, Vol. 4). Trad. Paulo César de Souza. São Paulo: Companhia das Letras, 2019.

FREUD, Sigmund. O Eu e o Id. [1923]. (Edição Cia das Letras das Obras Psicológicas Completas de Sigmund Freud, Vol. 16). Trad. Paulo César de Souza. São Paulo: Companhia das Letras, 2011. 
FREUD, Sigmund. Além do princípio do prazer. [1920]. (Edição Cia das Letras das Obras Psicológicas Completas de Sigmund Freud, Vol. 14). Trad. Paulo César de Souza. São Paulo: Companhia das Letras, 2010.

FREUD, Sigmund. Inconsciente. [1915a]. (Edição Cia das Letras das Obras Psicológicas Completas de Sigmund Freud, Vol. 12). Trad. Paulo César de Souza. São Paulo: Companhia das Letras, 2010.

FREUD, Sigmund. Observações sobre o amor de transferência. [1915b]. (Edição Cia das Letras das Obras Psicológicas Completas de Sigmund Freud, Vol. 10). Trad. Paulo César de Souza. São Paulo: Companhia das Letras, 2010.

FREUD, Sigmund. Algumas observações sobre o conceito de inconsciente. [1912a]. (Edição Cia das Letras das Obras Psicológicas Completas de Sigmund Freud, Vol. 10). Trad. Paulo César de Souza. São Paulo: Companhia das Letras, 2010.

FREUD, Sigmund. A dinâmica da transferência. [1912b]. (Edição Cia das Letras das Obras Psicológicas Completas de Sigmund Freud, Vol. 10). Trad. Paulo César de Souza. São Paulo: Companhia das Letras, 2010.

HALBWACHS, Maurice. A Memória Coletiva. Trad. Beatriz Sidou. São Paulo: Centauro, 2006. HOLZER, Werther. A Geografia Humanista: sua trajetória 1950-1990. Londrina: Eduel, 2016.

HOLZER, Werther. O método fenomenológico: humanismo e a construção de uma nova geografia. IN: ROSENDHAL, Z. et al. Temas e caminhos da Geografia Cultural. EdUERJ, 2010. p. 37-71.

HUYSEN, Andreas. Seduzidos pela memória. Rio de Janeiro: Aeroplano, 2000.

KINGSBURY, Paul \& PILE, Steve (orgs). Psychoanalytic Geographies. Burlington, VA: Ashgate, 2014.

LACAN, Jacques. O seminário, livro 5: as formações do inconsciente, 1957-1958. Rio de Janeiro: Jorge Zahar, 1999.

LACAN, Jacques. O seminário, livro 8: a transferência, 1960-1961. Rio de Janeiro: Jorge Zahar, 2010.

LACAN, Jacques. O seminário, livro 9: a identificação, 1961-1962. Trad. Ivan Corrêa e Marcos Bagno. Recife: Centro de Estudos Freudianos do Recife, 2003.

LAPLANCHE, Jean; PONTALIS, Jean Bertrand. Vocabulário da Psicanálise. São Paulo: Martins Fontes, 1997.

LOWENTHAL, David. The past is a foreign country - Revisited. Cambridge, Cambrigde University Press, 2015.

LOWENTHAL, David. Geography, experience, and imagination: towards a geographical epistemology. Annals of the Association of American Geographers, v. 51, n. 3, p. 241-260, 1961.

MARANDOLA JR., Eduardo; DE PAULA, Fernanda Cristina; PIRES, Maria Conceição Silvério. Diários de campo: aproximações metodológicas a partir da experiência metropolitana (Campinas e Santos). Novas metrópoles paulistas: população, vulnerabilidade e segregação. Campinas: Nepo/Unicamp, 2006, p. 459-491. 
MARANDOLA JR., Eduardo José. Habitar em risco: mobilidade e vulnerabilidade na experiência metropolitana. São Paulo: Blucher, 2014.

MIRANDA, Sonia. Regina \& SIMAN, Lana Mara Castro. Cidade, Memória e Educação. Juiz de Fora: Editora UFJF, 2013.

NORA, Pierre. Entre memória e história: a problemática dos lugares. Revista Projeto História. São Paulo: PUC, dez. 1993, no 10.

PILE, Steve. Real cities: modernity, space and the phantasmagorias of city life. Sage: London, Thousand Oaks, CA and New Delhi, 2005.

RELPH, E. Reflexões sobre a emergência, aspecto e essência de lugar. In: MARANDOLA JR, E. \& HOLZER, W. \& OLIVEIRA, L.(orgs.) Qual o espaço do lugar? São Paulo: Perspectiva, 2012. p. 17-31.

POLLAK, Michael. Memória, Esquecimento, Silêncio. Estudos Históricos, Rio de Janeiro, vol.2, n3, 1989.

RICOEUR, Paul. A Memória, a História, o esquecimento. Campinas: Editora da Unicamp, 2007.

SARAMAGO, L. O pensamento do lugar em Heidegger. In: MARANDOLA JR., E. \& HOLZER, W. \& OLIVEIRA, L.(orgs.) Qual o espaço do lugar? São Paulo: Perspectiva, 2012. p. 193-225.

SCHAMA, Simon. Paisagem e Memória. Trad. Hildegard Feist. São Paulo: Cia das Letras, 1996.

TUAN, Yi-Fu. Espaço e lugar - a perspectiva da experiência. Trad. Lívia de Oliveira. Londrina: EDUEL, 2013.

TUAN, Yi-Fu. Topofilia. Um estudo da percepção, atitudes e valores do meio ambiente. Londrina: Eduel, 2012.

WRIGHT, John K. Terrae incognitae: The place of the imagination in geography. Annals of the Association of American Geographers, v. 37, n. 1, p. 1-15, 1947. 